\title{
Bazı oral rehidrasyon çözeltilerinin sütün pıhtılaşması üzerine etkileri
}

\author{
Hüseyin VOYVODA', Bülent ULUTAŞ', Serdar PAŞA', Muharrem BALKAYA², \\ Mehmet Besim ÖZLEM ${ }^{1}$ \\ ' Adnan Menderes Universitesi. Veteriner Fakültesi. Iç Hastalıkları Anabiliın Dalı. Aydın: ${ }^{2}$ Adnan Menderes Ciniversitesi. \\ Vecriner Fakültcsi. Fizyoloji Anabilim Dalı, Aydn
}

\begin{abstract}
Özet: Bu çalışmada, 3 ticari (Electrolyte. Ge-Oral. Lectade) ve 2 özel haz̧ırlanan (asctat içeren ve alkallileștirici ctkeı içcrmeyen) oral rehidrasyon çözeltisinin (ORC) sütün pıhtılaşması üzcrine etkisi in vitro olarak incelendi. Cözzelti olanak: tam inek

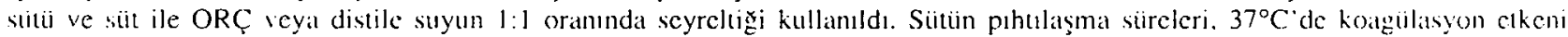

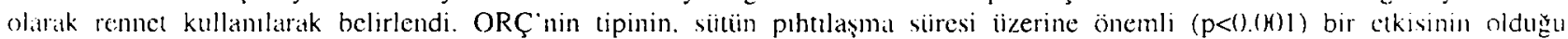

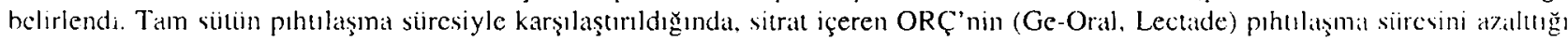

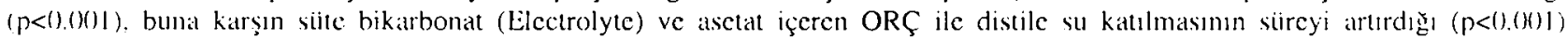

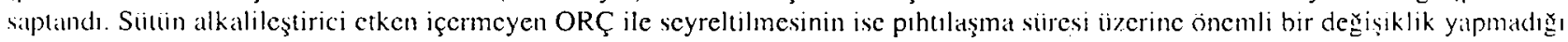

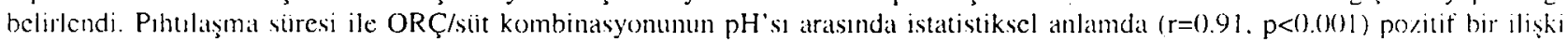
bulundu. Sonuç olarak. buzağılarda sütün kısa sürede pıhulaşması ile birlikte katnın alkalileştirilmesi isıcnildiğinde. sitrat içeren

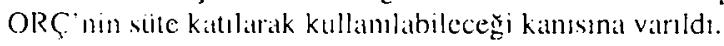

Anchtar kelimeler: Oral rchidrasyon çözcltisi. pıhtılaş̣ma. süt

\section{Effects of some oral rehydration solutions on clotting of milk}

Surnmary: In this study, the effect of 3 commercially (Electrolyte. Ge-Oral, Lectade) and 2 speciatly (onc atcelitte-containing and one without an alkalinizing agent) formulated oral rehydration solution (ORS) on clotting of milk was investiguted in betre. The solutions tested were whole fresh cow's milk and 1:1 dilutions of milk and ORS or distilled water. Milk clotting times were detcrmined at $37^{\circ} \mathrm{C}$. using rennet as the clotting agent. The type of ORS had a significant effect (p<0.(0)1) on milk clotting time. In comparison with clotting time of whole milk. citrate-containing ORSs (Ge-Oral. Lectade) decreased clotting time significintly $(p<(),(0) 1)$. whereas ORS that contained bicarbonate (Electrolyte) or acetate and diluting milk with distilled water increalsed it significantly $(p<0.0(0))$. Addition of solution that did not contain alkalinizing agent had no interference on clotting time $A$ significant positive corrclation $(r=0.91, \mathrm{p}<0.0() \mathrm{I})$ between clotting time and $\mathrm{pH}$ of ORS/milk combination had becn ohscrved. It was concluded that citrate-containing ORSs could be used in calves by adding to milk when alkalinization of blood along with rapid milk clotimg wats desired

Key words: Cloting. milk, oral rehydration solution

\section{Giriş}

Yeni doğan buzağılarda ishal: profilaksi ve sağaltın alammdaki tuin gelişmelere rağgmen günümüzde de yaygın olarak görüimekte ve ölümlerle doğrudan; gelişmede duraklama ve sağgalım giclerleri ile de dolaylı şekilde ckonomik kayıplara yol açmaktadır. Baßı işletmelerde yeni doğan buzağgların \%90-100'ünün ishalden etkilenmesi (27). isha'e bağlı ölümlerin diğer tüm buzağı hastalıklanudan ileri gelen kayıplardan fazlà olması (19) ve ckonomik \%ararn ïlkemizde de yüksek olduğu (33) şeklindcki bildirimler. sorunun boyutarm ortaya koymaktadir.

Buðağ jshallerinin sağgaltumında başarı, ctyotropik uygulamalar yaunda sıvı-elektrolit kayıpları ve metabolik asidozisin kısa sürede dijzeltilmesi ile sağlanabilmekLedir (3.16.23.33). Bu amaçla dehidrasyonun \%8'e kadar olduğ olgularda sıvı sağalumının oral (12), şiddetli dehidrasyonlarda ise parenteral yolla başlayıp. idame sıvı uygulamasının oral olarak sürdürülmesi önerilnckledir $(16,18.30,33,36)$.

Oral rehidrasyon çözcltileri (ORÇ). bileşiminde bulunan katyonlar $\left(\mathrm{Na}^{+}, \mathrm{K}^{+}\right)$ve anyonlar $(\mathrm{HCO}$, veya asetat, sitrat ve laktat gibi $\mathrm{HCO}_{3}$-önciil maddclcri) ishalin neden olduğu sıvi-elektrolit kayıplarmm giderilmesi ve metabolik asidozisin düzcltilnesini. glikøz ve glisin gibi organik maddeler de enerji açığmm giderilmesi ve bağırsak emiliminin artırılmasını etkin bir şekilde sağlamaktadır $(3,12,18.22)$. ORC uygulamismmn kolay ve ckonomik olması (22.30). \%8'c kadar olan dehidrasyonun tek başına giderebilmesi (18.35) ve şiddetli dehidrasyonlarda da idanı sıvı ihtiyacını karşılaması (12.16.18.3.3) nedeniyle, ishalli bu\%ağılardal yaygın olarak kullanılmak tadir.

Buzağllarn preruminant dönemde (1. gün-3. hafta) aldıkları süt, abomazumda rennin olarak da bilinen ki mozinin etkisiyle pihtılaşır. Pıhtıda kareinat şeklinde kalan proteinler ile yağ globiilleri $12-18$ saal içinde sin- 
dirilirken, laktoz ve siil serumundaki proteinler çözcltide kalarak hızlı bir şekilde ince bağırsaklara geçer $(17,20)$. Süitün belirtilen prhtılaşma işleminin genel olarak sindirinni kolaylaşırıdı̆̆ı, ince bağırsaklarda protein ve karhonhidratların yuiksek konsantrasyonda bulunmasını engelleyerck patojen mikroorganizmaların çoğalmasını smurlandırdığı ve kanda üre ve amino asit konsantrasyonunun en iist noktaya ulaşmasını önlediği bildirilmektedir $(7,20,26)$. Sağhlklı buzağılara kısa sürede fazla miktarda suit verilmesi, sütün $\mathrm{pH}$ 'sının düşuik veya yüksek olması, lazla sıcak $\left(>40^{\circ} \mathrm{C}\right)$ veya soğuk $\left(<30^{\circ} \mathrm{C}\right)$ siitiin verilmesi ve sültekj kalsiyum miktarının düşük olması, abomazumda pıhtılaşmayı bozarak anorexia vitulorum'a $(8,20,32)$ veya ölüme (15) neden olabilmektedir. Ishalli buzağ larda ise, sıkça gelişen villus atrofisi ve emilim bozukluğu $(28,37)$ nedeniyle, sütün abomazumda pıhtılaşmasının daha fazla önem kazanacağı ve suitiın pıhtılaşmasındaki bozukluklara karşı duyarlılığın daha da arıacaפㄱ belirtilmoktedir (24).

Ishalli buzağılarda dehidrasyon ve metabolik asidozis gelişiminin önlenmesi veya giderilmesi amacıyla ORÇ sık kullanılmakla; ancak bu çözeltilerin özellikle uygulama şekli ve pH'sı konusunda farklı görïşler ileri siïriilmektedir $(10,12,13,16,31)$. Aydın yöresinde çalışan scrbest veteriner hekimler. ishalli buzağılarda bazı ORÇ' nin kullanıminda sindirim bozukluğu ve ölüm olaylarmun geliştiğini bildirmektedirler. Sorun. ORÇ'nin uygulama şcklindeki farklılıklardan kaynaklanabilir.

Bu f̧alışmada, farklı bileşimde 3 ticari ve 2 özcl hazmlanan ORÇ"nin sütuin pıhtılaşması üzerine ctkilerinin in vitro karşılaştırılarak, ORÇ'nin sütle birlikte kullanılabilirliğinin belirlenmesi amaçland.

\section{Materyal ve Metot}

Çalışmada, aymı lakıasyon dönemindeki sağlıklı incklerden săglanan lam çiğ süt, distile su ve bileşimleri Tablo l'de gösterilen ORÇ kullanıldı. Ticari ORÇ (Leclade: Ptïzer, Ge-Oral: Kansuk. Electrolyte; Provet) uiretici firmaların önerileri doğrultusunda, asetat içeren (AS) ve alkalileştirici etken içermeyen (AIS) ORÇ de bir litre distilc suya $2.9 \mathrm{~g}$ sodyum asetat (AS), $3.5 \mathrm{~g}$ sodyum klorür. 1.5 g potasyum klorir ve 20.2 g glikoz (Merck) katularak hazırland (21). Tam çiğ süt ve 1:1 oranında distile su veya ORÇ ile scyreltilen siit örneklerinin in vitro pih- tılaşma süresi, pıhtılaşma etkeni olarak rennet (Sig̣ma) kullanılarak $37^{\circ} \mathrm{C}$ 'de gerçekleştirildi.

Süt, ORÇ ve distile suyun $\mathrm{pH}$ değerleri $\left(\mathrm{pH}_{1}\right) \mathrm{pH}$ metre (Inolab Level 1, WTW) ile belirlendi. Bu\%ağ abomazumundan elde edilen rennet tip I (Sigma. R 3376) distile su ile $2500 \mathrm{mg} / 200 \mathrm{ml}$ konsantrasyonda olacak şckilde seyreltildi. Tam süt ile 1:1 oranında distile su veya ORÇ ile seyreltilen süi örnekleri, $50 \mathrm{ml}$ 'lik bölümui siyah bir bantla kapatılan 100 ml'lik beherlere $50 \mathrm{ml}$ konuldu ve $\mathrm{pH}$ değerleri $\left(\mathrm{pH}_{2}\right)$ tekrar ölçiildui. Hàırlanan rennel çözeltisinden süt örncklerine $0.5 \mathrm{ml}$ ilave edildi ve ren netin hızlı ve homojen bir şekilde dağılması sağlandı. Pıh tlaşma süresinin belirlenmesinde. cam bir hagel beherc her 5 saniyede bir daldırıldı ve ilk pıhılaşnıanın gïzlemlendiği ana kadar geçen süre kronometre (Synchro Sport 920, Trecise) ilc kaydedildi $(4,24)$. Pıhtının tam olarak oluşumundan sonra örncklerin $\mathrm{pH}$ ölçümii $\left(\mathrm{pH}_{3}\right)$ lekrarland. Tan süt ve distile su veya ORÇ ile sulandirylan süt örneklerinde $\mathrm{pH}$ ve pihtılaşma sürcsinin belirlenmesinde her bir çözelti için 10 örnck kullanıldı.

Tablo l'de belirtilen çözeltilerim bileşimi. uiretici fir maların formuilasyonu ve hazırlandığı kimyasal maddelerden hesaplandi.

Sayısal verilerin istatistiksel değerlendirilmesi. SPSS 7.0 istatistik programula yapıldı. Deg̣işkenlerin $\left(\mathrm{pH}_{1}, \mathrm{pH}_{2}, \mathrm{pH}_{3}\right.$, puhtılaşma süresi) grup ortalamalarmun karşılaşurıılması varyans analizi ile yapıldı. Gruplar ara sında istatistiksel bir fark çıktığında, farkın hangi gruptan kaynaklandığını saptamak için Tukey HSD testi kullanıldı. Pıhulaşma süresi üzerine $\mathrm{pH}^{\circ}$ nun etkisi ve ORÇ'nin bileşiminde bulunan glikoz ve elektrolitlerin $\left(\mathrm{Na}^{+}, \mathrm{K}^{+}, \mathrm{Cl}^{-}\right) \cdot$ pıhtılaşma süresi ile ilişkisinin belirlenmesinde, tek değişkenli ve çoklu linear regresyon analizi uygulandı (29).

\section{Bulgular}

Araştırmada kullanılan süi. distile su ve ORÇ’nin $\mathrm{pH}$ değerleri $\left(\mathrm{pH}_{1}\right)$ ilc süte $1: 1$ oranmda distile su veyal ORÇ katılmasının $\mathrm{pH}\left(\mathrm{pH}_{2}\right)$ ve pıhtılaşma süresine etkileri Tablo 2' de özetlendi. Tablo 3'de puhtılaşrna süresi ile ORÇ'nin pH1, $\mathrm{pH}_{2}$ (ORÇ/suit), glikuz ve elektrolit değerleri arasındaki ilişki belirtildi. Şekil l'de çözcltilerin $\mathrm{pH}$ 'sı $\left(\mathrm{pH}_{2}\right)$ ile pıhtılaşma süresi arasındaki ilişki gösterildi.

Tablo 1. Oral rehidrasyon çözcltilerinin bileşimi.

Table 1. Composition of oral rehydration solutions.

\begin{tabular}{|c|c|c|c|c|c|c|c|c|c|}
\hline Çozelii & Glikoz & Glisin & $\mathrm{Nat}$ & $\mathrm{K}+$ & $\mathrm{Cl}$ & Fosfat & Bikarbonal & Asctiat & Sitrat \\
\hline L.ectade & 113.0 & 41.2 & 73.4 & 15.5 & 73.3 & 15.0 & - & - & 1.28 \\
\hline Ge-Orial & 112.0 & - & 89.7 & 20.1 & 80.0 & - & - & - & 9.9 \\
\hline Filectrolyte & 58.5 & 24.0 & 79.6 & 10.7 & 60.4 & - & 30.9 & - & - \\
\hline$A S$ & 112.0 & - & 81.3 & 20.0 & 80.0 & - & - & 21.3 & . \\
\hline AlS & 112.0 & - & 81.3 & 20.0 & 80.0 & - & - & - & - \\
\hline
\end{tabular}

* Biitiin degerler. mmol/L'dir. 
Tablo 2. Distile su ve ORÇ’nin sütiin pH ve phtılaşma süresi üzerine etkileri.

Tabic 2. Effects of distilled water and oral rehydration solutions on milk pH and milk clotting time.

\begin{tabular}{|c|c|c|c|c|}
\hline Çorclti & $\begin{array}{c}\mathrm{pH}_{1} \\
\text { Sijt. distile su ve } \\
\text { ORÇ'nin pH's] } \\
\bar{X} \pm 5 \bar{x}\end{array}$ & 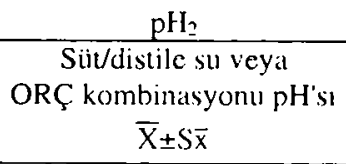 & $\begin{array}{c}\mathrm{pH}_{3} \\
\text { Pıhtılaşma sonu } \\
\mathrm{pH} \\
\bar{X} \pm S \bar{x}\end{array}$ & $\begin{array}{c}\text { Pihulașma siiresi } \\
(\text { sn) } \\
\overline{\mathrm{X}} \pm \mathrm{S} \overline{\mathrm{x}}\end{array}$ \\
\hline Siil & $6.51 \pm 0.020 \mathrm{~d}$ & $6.51 \pm 0.020^{\circ}$ & $6.50 \pm 0.014^{d}$ & $177.5 \pm 7.46$ \\
\hline Distile su/süt & $5.56 \pm 0.107$ & $6.71 \pm 0.007$ & $6.75 \pm 0.019$ & $331.6 \pm 16.45^{\prime}$ \\
\hline Lectade/süt & $3.99 \pm 0.010)^{2}$ & $6.27 \pm 0.0088^{c}$ & $6.27 \pm 0.012$ & $98.4 \pm 4.35^{d}$ \\
\hline Gc-Oral/süt & $7.77 \pm 0.0008^{h}$ & $5.97 \pm 0.014$ & $5.77 \pm 0.052^{\prime}$ & $65.7 \pm 6.34^{i i}$ \\
\hline Electrolyte/suit & $8.50 \pm 0.015^{a}$ & $6.72 \pm 0.025^{a}$ & $6.62 \pm 0.045^{\circ}$ & $335.1 \pm 69.77$ \\
\hline AS/süt & $7.21 \pm 0.015^{\circ}$ & $6.66 \pm 0.011^{\mathrm{h}}$ & $6.66 \pm 0.013^{\mathrm{h}}$ & $284.2 \pm 20.45^{h}$ \\
\hline AlS/suit & $6.15 \pm 0.1138^{\circ}$ & $6.54 \pm 0.0\left(14^{\circ}\right.$ & $6.52 \pm 0.009 \mathrm{~d}$ & $198.8 \pm 7.22^{\circ}$ \\
\hline
\end{tabular}

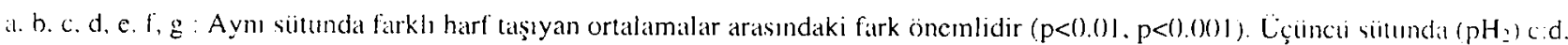

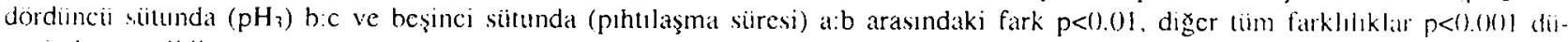
zcyinde önemlidir.

Tablo 3. Pshtulaşma süresi ile ORÇ’nin pH. glikoz ve elektrolit değerleri arasındaki ilişki.

Table 3. Relittonship between milk clotting time and pH, glucose and electrolyte values of oral rehydration solutions.

\begin{tabular}{|c|c|c|c|}
\hline B ilğ & 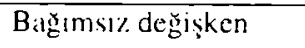 & $\mathrm{r}$ & $p$ \\
\hline Pohulaşma siresi & $\mathrm{pH}$ & 0.494 & $\mathrm{p}<0.0(01$ \\
\hline Prhulaşma :sïresi & $\mathrm{pH}_{2}$ & 0.909 & $\mathrm{p}<0.0(0) 1$ \\
\hline Pıhtılaşına süresi & $\mathrm{pH}_{2}, \mathrm{pH}_{1}$ & 0.952 & $\mathrm{p}<0.001$ \\
\hline Pıhulaşma siurcsi & Glikoz & -0.638 & $p<0.001$ \\
\hline Pıholașma siurcsi & Sodyum & -0.200 & $p>0.05$ \\
\hline Pihtrlaşma siiresi & Potasyum & $-(0.428$ & $p<0.00) 1$ \\
\hline Pihulaşma suresi & Klor & -0.500 & $p<0.001$ \\
\hline Pihulisşmá süresi & Gliko\%. Klor. Sodyum & 0.925 & $p<0.00()]$ \\
\hline
\end{tabular}

Varyans analizi, gruplarun $\mathrm{pH}_{\rfloor}, \mathrm{pH}_{2}$ ve $\mathrm{pH}_{3}$ ortalamaları arasındaki farkın önemli olduğunu gösterdi $(\mathrm{p}<0.001)$. Sïtüun $\mathrm{pH}$ değcri $\left(\mathrm{pH}_{1}\right)$ ile karşılaştırıldığında, distile su. Lectade ve alkalileştirici etken içermeyen (AIS) ORÇ'nin pH'sının önemli dizeyde $(\mathrm{p}<0.001)$ diişiik. buna karşın Ge-Oral, Electrolyte ve asetat içeren
(AS) ORÇ'nin pH'sının önemli dü $\measuredangle c y d e(p<0.001)$ yük sek olduğu belirlendi (Tablo 2).

Süte 1:1 oranında distile su veya ORÇ katılmasınm $\mathrm{pH}$ değerinde önemli değgişiklikler yaptığı saptandı. Tam çiğ sütün $6.5 \mathrm{l} \pm 0.02$ olan ortalama $\mathrm{pH}^{\prime} \mathrm{s}$ ( $\left(\mathrm{pH}_{2}\right)$. Leclade $(6.27 \pm 0.008)$ ve Ge-Oral $(5.97 \pm 0.014)$ katılmasılal $\mathrm{p}<0.001$ düzeyinde azalmá, distile su $(6.71 \pm 0.0(07)$ ile Electrolyte $(6.72 \pm 0.025)$ ve asetat içeren ORC $(6.66 \pm 0.011)$ katılmasıyla $\mathrm{p}<0.001$, alkalileştirici elken içermeyen ORÇ'de $(6.54 \pm 0.004)$ ise $p<0.01$ düzcyinde artıs gösterdi (Tablo 2). Sütün pihtılaşma sonu pH’sına $\left(\mathrm{pH}_{3}\right)$ göre; Lectade ve Ge-Oral/suit kombinasyonu $\mathrm{pH}_{3}$ değerleri önenlli düzeyde düşüik $(\mathrm{p}<0.00) 1)$, distile su. Electrolyte ve $\mathrm{AS} / \mathrm{süt}$ kombinasyonlarmun pıhılaşma sonu pH'sının ise önemli duizeyde yüksek $(p<0.001)$ olduğu belirlendi. Süt ile AIS/süt kombinasyonlarının $\mathrm{pH}_{3}$ ortalamaları arasındaki fark anlamlı bulummadı.

Varyanz analizi, kullanılan ORÇ tipinin sütün pıhtılaşma süresi üzerine öncnli bir ctkisinin olduğgunu gös-

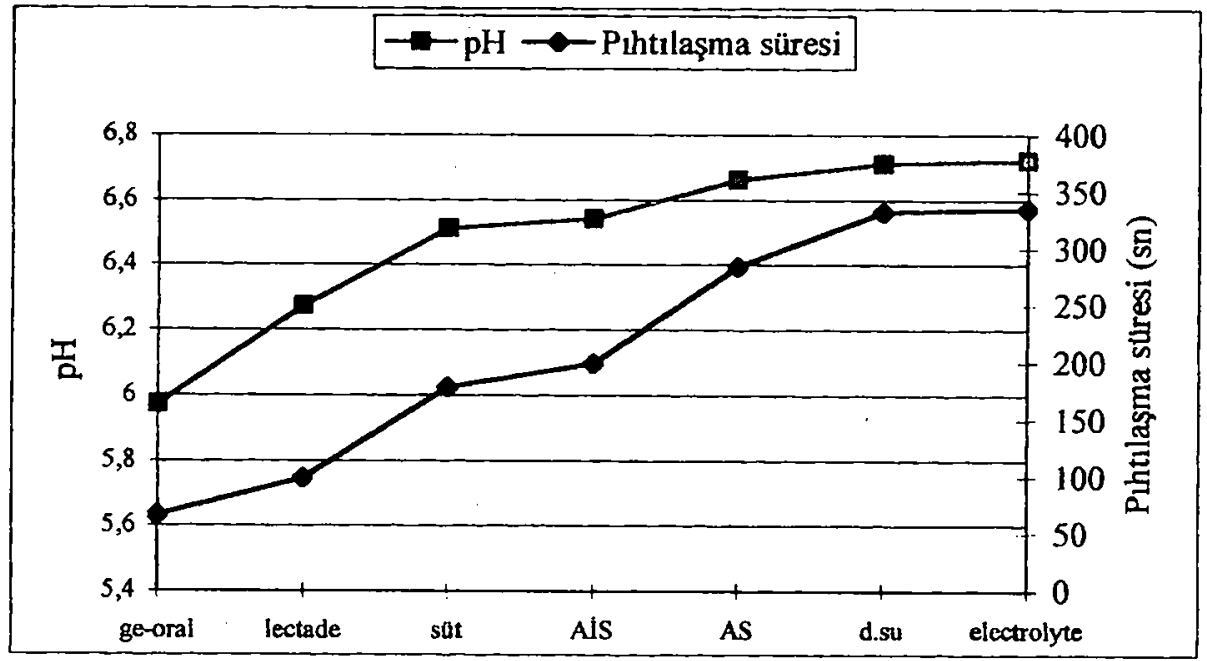

Şckil-J. Pıhuılaşına süresi ilc çözeltilcrin pH'sı $\left(\mathrm{pH}_{2}\right)$ arasıındaki ilişki.

Figurc-1. Relationship between milk clotting time and $\mathrm{pH}$ of solutions. 
terdi $(p<0.001)$. Sütün pihtılaşma süresi ile karşılaştınldığnda, suite sitrat içeren ORÇ'nin (Lectade, Ge-Oral) kaulmasımın pihtılaşma süresini kısaltuğ $(\mathrm{p}<0.001)$, bikurbonat (Electrolytc) ve aselat içeren (AS) ORÇ ile dislile suyun ise bu siireyi uzattı̆̆ göruildü $(p<0.001)$. Buna karşın. süle alkalileştirici etken içermeyen çözeltinin (AIS) katılmasının pihtılaşma süresi üzerine önemli bir cikisinin olmadığ belirlendi (Tablo 2)

lek bağımsız deģiskenli regresyon analizi, pihIılaşma süresi jle ORÇ ve ORÇ/süt kombinasyonlarının $\mathrm{pH}^{\prime} \mathrm{s}$ arasında pozitif, ORÇ'nin glikoz, potasyum ve klor konsantrasyonları arasında ise negatif önemli bir ilişki olduğ unu gösterdi (Tablo 3). Adım adım seçme ve cleme vöntemiyle yapılan regresyon analizinde de, pihtılaşma süresi ile her iki $\mathrm{pH}$ arassnda önemli pozitif ilişki be. lirlendi (Tablo 3). Çoklu regresyon analizi; çözeltide gliko\% ve sodyum konsantrasyomunun diişük. klor konaintrasyonunun ise yuiksek olması durumunda pıhtılaşma süresinin artuğ

\section{Tartışma ve Sonuç}

Ü̧ haftalıktan küçüik buzağllarda sütün abomazumda rennin etkisiyle pihtılaşması, özellikle protein veya yặ sindirimi açısından büyüuk önem taşımakıadır $(20,24)$ Belirtilen yaşlaki sağlıklı buzağılarda sittün abomazumda phhulaşmasının engellenmesi veya gecikmesi, bağırsaklara yoğun protein geçişi ve bakleri florasında artış ile ishalin göruilme sıklığ zağlarm ise, farklı diizeylerdeki villus atrofisi ve emilim bozukluğu (28.37) nedeniyle, sütiin puhtılaşmasındaki bozukluklara karşı daha duyarlı olacağı ve pıhtılaşma sü resinin öneminin daha da artabilecegi belirtilmektedir (24). Aydn yöresinde çalışan serbest veteriner hekimlerin ishalli buzağılarda bazı ORÇ'nin kullanımında kirş̧laşukları sorunun. ORÇ'nin bileşimi ve sütle birlikte rerilmesinden kaynaklanabileceğj düşuiniildui. Bu amaçla, farklı bileşinde 5 ORÇ ile distile suyun 1:1 oranında süte katılmasmm prhulaşma süresi ïzerine ctkileri in vitro olarak incelendi.

Suitiin $\mathrm{pH}^{\prime} \mathrm{s}$ bir türden diğerine, kimyasal bileşimine. laktasyon dönemi ve beslenmeye bağl olarak değişiklik göslermekte (17.34) ve normal inek sütlerinde 6.7 00.05 (24), 6.5-6.9 (25) olarak bildirilmektedir. Bu çalişmada kullanılan çiğ inck siituinüin ortalama $\mathrm{pH}$ değcri $6.51 \pm 0.02$ olarak belirlendi ve değerin literatür bildirimleriyle uyumlu olduğ görüildü.

Süttin rennet ile pıhtılaşma süresi. sütteki tu\% (özcllikle kalsiyum) konsantrasyonu, siituin kappa-kazein miktarı, stcaklığ 1 ve pH değeri ile katılan rennetin miktar ve aklivitesine bağlı olarak değişiklik göstermektedir (8.17.25,34). Rennel ile pH's 6.5 olan suitün 180-240 saniye arasinda (20), ortalama pH's $6.7 \pm 0.05$ olan 37 C'dcki inek siituinuin $214 \pm 18$ saniyede (24) pihtılaştığ bildimektedir. Bu çalışmada, sıcaklığı $37^{\circ} \mathrm{C}$ ve pH'sı
$6.51 \pm 0.02$ olan inek sütünün rennel ile phtılaşma süresi 177.5 \pm 7.46 sn olarak belirlendi (Tablo 2). Belirlenen ph. tılaşma süresinin Naylor (24)'un bildirdiğ süreye göro daha kısa olması. yukarda pıhtılaşma suiresini etkilediğ bildirilmiş olan faktörlerden kaynaklanmış olabilir

Ishalli buzağılarda gelişen sıvı.elckırolit kalyıplan ve enerji açı̆̆ının karşılanmasında, uyğulamasimun kolaly ic ekonomik olması nedeniylc ORÇ sık kullanılnakla: ancak bu çözeltilerin özellikle uyg̣ulama şckli ve $\mathrm{pH}^{\circ} \mathrm{s}$ konusunda farklı görïşler ileri sürülmekledir. Hoffmann (14), ishalli buzağllara 1-2 giin siituin verilmesinin $\mathrm{kc}$ silerek sadece ORÇ kullanımını önerirken. Hartmann (12) ve Klec (16) ORÇ'nin tek başma kullammmnın iegatif enerji dengesi ile rayıflamaya sindirim enzinnlerinin aktivitesinde azalma ile de sindirim bozukluğuna yol alçalbileceğini bildimektedirler. Siitün rennin ile pubtulşmast ve pıhtıdaki kazeinatın proteolizisi için. abomazum içeriğinin pH'sının dïşük olması gerckmekıedir (12.2()). Buzağllara ORÇ süte katılarak verildiğinde. çïzcltinin içerdiği alkalileştirici anyonun $\mathrm{Ca}^{++}$iyonları ile kompleks. oluşturarak vey'a pH'y artırarak pshtı oltışumumu engelleyebildiği ve bu yolla sindirim ve bağgrsak bozukluğunun gelişcbildiğg belirtilnekledir (4.10)-13). Kallsiyum içermeyen ORÇ’nin siitle birlikte verilntesi. su landırma etkisiyle abomazum içeriğinde kalsiyum konsantrasyonunu azaltarak sütün pihtılaşma süresinin uzamasina ve sindirim bozukluğuna neden olabilmektedir (4,10,12). Simmons ve ark. (31), asidik ORÇ'nin aho-

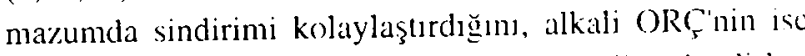

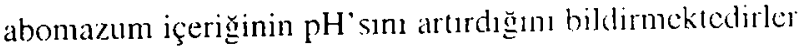
Bu çalışmada da süte ORÇ katılmasımmn pıhtılaş̆ma sütresı iizerine önemli bir ctkisinin $(p<0.001)$ olduğ ve elkinin ORÇ'nin bileşiminde alkalileştirici bir čkenin bulunup bulunmamas ile etkenin tipine hağh olarak değgşiğ he lirlenerck, sitrat içeren Ge-Oral'm en kısa sïrede pih ılaşna sağladığı görüldü (Tablo 2)

Ishalli buzağglarda metabolik asidozisin intenmesi veya duizeltilmesi için, kullanilan ORÇ'nin bileşiminde $\mathrm{HCO}_{3}$ veya sitrat, asetat ve laktat gihi $\mathrm{HCO}:{ }^{-}$- onciil maddelerinden hir alkalileştirici etken bulummalıdır $(3,12.22)$. Çalışmada, süte sitrăt içeren ORÇ’nin katılmassmun pıthtılaşma süresini azalıtı̆̆ bikarbonal ve asetal içeren ORÇ'nin ise bu süreyi artırdığ belirlendi (Tablo 2). Pıhulaşma süresi ile ORÇ/süt kombinasyonun pH'sı arasında $\mathrm{p}<0.001$ diizeyindeki poritif ilişki (Tablo 3. Şekil 1). kal-

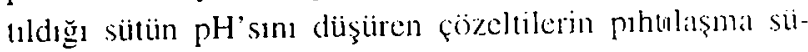
resini azalttı̆gnı göstermcktedir (Tablo 2). Sültc asilliğgin artması, rennetin ctkisini kolaylaşırmak ve sütüı pıttulaşmasına karşı direnci sağlayan tu\% dengesini bozmak suretiyle pıhtılaşmayı hızlandırmaktadır (25,34). Bu çalısmada, sitrat içeren ORÇ'nin siituin $\mathrm{pH}$ 'sın $6.51^{\circ} \mathrm{den}$ 5.97 (Ge-Oral) ve 6.27 ye (Lectade) diiş̧iirerek asilliğgini arturdığ $(p<0.001)$, buna bağhı olarak da pihtılaşma sijresini önemli düzeyde $(p<0.001)$ araltuğ belirlendi 
(Tablo 2). Ge-Oral' in Lectade' a göre sütün pH'sını daha fazla diişümesi ve istatistiksel anlamlı olmamakla birlikte daha kısá pıhtılaşma süiresi sağlaması (Tablo 2), bu ORÇ: nin bileşiminde daha fazla sitrat bulunmasından (9.9 mmol/L) kaynaklanabilir. I_ectade' in da $1.28 \mathrm{mmol} /$ L gihi diişïk konsantrasyonda sitrat içermesine rağmen sütün pH ve pıhtılaşma süresini önemli düzeyde azaltması (Tablo 2), bileşininde sitral dişında fosfat bulunması ile açıklanabilir. Fosfat doğrudan sütün pıhulaşmasını etkilcmenektedir (9). ORÇ'de fosfat, asit losfat tl:zlari şcklinde bulummaktat. bu da pH'yı azaltmaktadı (24). Bileşinninde $1.28 \mathrm{mmol} / \mathrm{L}$ ve $15 \mathrm{mmol} / \mathrm{L}$ fosfat hulunan I.eclade'1n süte katılmasinda $98.4 \pm 4.35 \mathrm{sn}$ olarak belirlenen pıhulaşma süresi (Tablo 2), $1.6 \mathrm{mmol} / \mathrm{L}$ sitrat ve $16 \mathrm{mmol} / \mathrm{L}$ fosfat içeren ORÇ'nin süte kaulmasıncia $96 \pm 8$ sn olarak bildirilen (24) pihtılaşma sijresiyle uyumlu bulundu. Buna karşn. $9.9 \mathrm{mmol} / \mathrm{L}$ sitrat

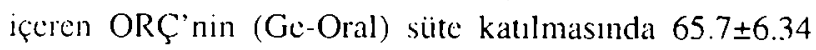
sn olarak belirlenen pihulaşma süresi, $13.3 \mathrm{mmol} / \mathrm{L}$ sitrat içeren ORÇ’nin süte katulmasında 600 saniyeden fazla (24) ve $14 \mathrm{mmol}$ sodyum sitratun $\mathrm{pH}$ 's 5.5 olan süt tozuna ilavesinde 1.32 sn (9) olarak bildirilen pıhtılaşma sürelerine uymamaktadır. Bu durum, Ge-Oral'ın bileşiminde buluran glikoz ve potasyum konsantrasyonunun (Tablo 1) $13.3 \mathrm{mmol} / \mathrm{L}$ - sitrat içeren ORC' deki glikoz (60) mmol/L) ve polasyum (15 mmol/L) konsantrasyonundan fazla olmasi ve süt tozuna katılan sodyum sitrat dişincla phoulaşmada rol oynayan diğer maddeleri de (24) içermesi ile açıklanabilir. Pıhtılaşma süresi ile ORÇ’nin bileşinindeki glikoz ve potasyum konsantrasyonu arasında belirlenen önemli negatif ilişki (Tablo 3), ORÇ'nin bileşiminde glikoz ve polasyum konsantrasyonu azaldıkça pıhulaşma süresinin artığını göstermekte ve aym yöndcki bildirimle (24) açıklamayı desteklemektedir. Naylor (24). siite katılan $40 \mathrm{mmol} / \mathrm{L}$ 'den fazla sitratın pihtulaşmaly engellediğ $\mathrm{Ca}^{++}$iyonları ile kompleks olışıurmasına dayandırılmakladır. Ge-(Oral ve Lectade'm bileşinninde bulunan sitrat koısantrasyonları. sütün pıhtılaşmasını engellediği bildirilen diizıyden oldukf̧a dïşüktür.

Bikarbonal içeren oral elektrolit çözeltilerinin sütün pıhılaşmasını engellediği (4). abomazumun boşalmasını hızlandırdı (1) ve muhtemelen de bağırsağ geçiş süresini aðaltığı (1.3) bildirilmektedir. Sağlıklı buzağılara bikarbonat içeren ORC süte 1:1 oramnda katularak veruldiğgnde, ishalin görülme sıklığını önemli dïzeyde arttığ belirtilmektedir (4). Heath ve ark. (13), ishalli buza⿳̆冖̆lara $80 \mathrm{mmmol} / \mathrm{L}$ bikarbonat içeren oral elektrolit çözeltisi verildiğinde, abomazumdaki asidik ortamın nötralizasyonu ve sütiin pıhtılaşmasının engellenmesi yoIıyla canlı ağırlık arlışının azaldığın bildirmektedirler. Belirtilen nedenlerden dolayı bikarbonat içeren ORÇ'nin süllc birlikte kullanılması önerilmemektedir $(13,16)$. Naylor (24), $75.5 \mathrm{mmol} / \mathrm{L}$ hikarbonat içeren ORÇ'nin in vitro koşullarda sütún rennet ile phohılaşna süressinı önemli diü. zeyde artırdığını saptamıştır. Bu çalışmada. $30.9 \mathrm{mmmol} / \mathrm{I}$ bikarbonat içeren ORÇ’nin prhtılaşma süiresini änemli duizeyde arturması, bu çözeltinin ilave edildiği sijtün $\mathrm{pH}^{\prime} s \mathrm{~m}$ 6.51 'den 6.72 ye yükseltmesi ile açıklanahilir (Tablo 2).

Oral rehidrasyon çözeltilerinde bulunan asctatun alkalileştirici etken olması yanmda sodyum alımını desteklediği, bikarbonattan farklı olarak abomazumdaki asiditcyi azaltmadığı bildirilmektcdir (22). Bileşiminde sitralt da bulunan $80 \mathrm{~mm} o l / L$ asctat içcren ORÇ $n$ nin sütün rennet ile in vitro pıhtılaşma süresini önemli dü\%evde de ğiştirmemesi, buna karşın $60 \mathrm{mmol} / \mathrm{L}$ aselal içeren ORÇ’nin bu süreyi artırması (24), asclat içeren ORÇ“nin sütün pıhtılaşma süresi üzerine miktara bağlı etki yaptığını göstcrmektedir. Bu çalışnıada $21.3 \mathrm{~mm} / \mathrm{l} / \mathrm{L}_{\text {asctat }}$ içeren ORÇ’nin sütün pihtılaşma süiresini artırması, $\mathrm{pH}$ `s

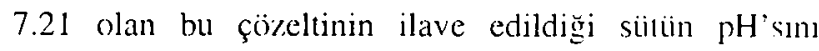
6.51 'den 6.66'ya yuikseltmesine yorumlanabilir (Tablo 2).

Alkalileştirici etken içermeyen ORÇ゙nin süte katılmasının pıhtılaşmayı olumsuz elkilemedjğ hildirimine (24) benzer olarak bu çalışmada. Als kalılan suilün pihtılaşma süresinde öncmli bir doğ̣işjklik helirlenmedi (Tablo 2). Bu durum, ORÇ/süt kombinasyonunda. pıhtılaşma süresini öncelikle ORÇ'nin bileşiminde hulunan alkalileştirici etkenin etkilediğini göstermektcdir. Tanıpon madde dişında ORÇ'nin bileşiminde bulunan gliko\% ve potasyum konsantrasyonu ile pshulaşmal süresi arasında istatistiksel anlanda negatif bir ilişki bulunduğ ve ilişkinin nedeninin bilinmediğ belirtilmektedir (24). Süte katılan sodyum klorïrün de pıhulaşma sırasında oluşan reaksiyonları (34) ve rennetin pıhtılaşurma aklivitesini (6) etkilediği bildirilmektedir. Bu çalısmada da. tek değişkenli regresyon analiziyle ORÇ/süt kombinasyonunun pihtılaşma süresi ile ORÇ nin bileşimindeki glikn\% potasyum ve klor konsantrasyonu arasmda negatif ilişki ol. duğu (Tablo 3). cn uzun puhtılaşma suiresinin (Tablo 2) glikoz, potasyum ve klor konsantrasyonu en dişük olan çözcltide (Tablo 1. Electrolyte) bulunduğ belirlendi. Pıhtılaşma süresi ile ORÇ'nin bileşimindekj glikoz ve clekırolitler arasındaki ilişkinin birlikıc deģerlendirildiği çoklu regresyon analizi, çözcltide glikoz ve sodyumun düşik. klorun ise yuiksck konsantrasyonda bulumması durumunda pıhtılaşma süresinin artığını gösterdi. Sütün pıhtılaşma süresini en fazla artıran Electrolyte'in bileșimindeki gli koz ve kısmen de sodyum konsantrasyonu foklu reg resyon analizi sonucuyla uyumlu. klor konsantrasyonu ise farklıdır (Tablo 1). Bu analiz yönteminde potasyun ve sodyumda ilişki, klor da ise ilişkinin yöniinuin tek de ğişkenli regresyon analizinden farklı bulumnası, hağımsı». değişkenlerin birbirini etkilemelerinden (29) kaynaklana bilir.

Buzağylara verilen siitün su ile seyreltilehileceğ ancak abomazumda pihtılaşmayı bozmalmass içiı su landırmanın \%,10-20'yi geçmemesi gercktiğ bilcirrilmek 
1edir (14). Süte su katılması asitlig̨ ve aym zamanda kalsiyum miktarın dïşürerek prhtılaşma yeteneğini azaltmaktadır $(12,34)$. Bu çalı̧̧̧mada da, süte $1: 1$ oranında distile su katılmasımın, süttiı pH`sı ve pıhtılaşma süresinde önemli artı̧̧a neden olduğu belirkendi (Tablo 2). Pratikte bu/ağ 1 lara verilen sütiin sulandırılmasında, $\mathrm{pH} ' \sin ı n$ 6.5 9.2 arasmda bulunduğ bildirilen (5) içme suyu kullanılmaktadır. Içme suyunun pH'sı ve bileşimi bölgeden bölgeye büyuik değişiklikler gösterdiğinden, bu çalışmada sulandırmamn sütün pihulaşma süresi üzerine etkisinin belinlenmesinde $\mathrm{pH}$ 's $5.56 \pm 0.107$ olan distile su (Tablo 2) tercih edildi.

Sindirim ile ilgili birçok fïzyolojik ve patolojik olayin değerlendirilmesinde in vitro testlerden yararlanılmakıadır $(2,8)$. Bu çalışmada, süte ORÇ katılmasının pıht1aşma süresine etkisi in vitro ortanda rennet ilc belirlendi. Sütün abomazumndaki prhtılaşmasını rennin aktivilesi yanında ortamin $\mathrm{pH}$ 's1, tampon madde ve elektrolit yoğunluğu ctkilemektedir $(17,20,24)$. Süte ORÇ katılınasının pihtılaşma süresine etkisi in vitro ortamda abomazum sivısı kullanarak da incelenmiş ve pıhtılaşma süresinin ORÇ'nin bileşimine bağh olarak değiştiği belirlenmiştir (24). Değişik nedenlerden dolayı in vitro testler, in vivo ortamdaki değişimleri her zaman tam olarak yansıtmayabilir (2,8). Bu nedenle, sütc ORÇ katılnısının prhtılaşma sürcsi üzerine etkisinin in vivo koşullarda be lirlenmesi. değişinlleri daha objektif ortaya koyabilir.

Sonuç olarak, süte sitrat içeren ORÇ (Ge-Oral, Leclade) katılmasımın pihtılaşma süresini azalttığı, bikarbonat (Electrolyte) ve asetat içeren ORÇ'nin ise bu süreyi arturdığı belirlendi. Bu sonuçlara göre; preruminant dönemdeki buzağılara pihtılaşma süresini artıran ORC'nin süte katılarak verilmesinin uygun olmayacağı, sitrat içeren ORC'nin ise sütle birlikte kullanılabilecç̆g kanusina varıldı.

\section{Kaynaklar}

1. Bell FR, Mostagni K (1975): Duodenal control of gastric: emprying in the milk-fed calf. J Physiol. 245. 387-407.

2. Bolton LI, Pines E, Rovee DT (1988): Wound Healing and Integumentary System. Chapter 1, 1-9. In: MM Schwindle. RJ Adams (Eds). Experimental Surgery and Physiology. Included Animal Models of Human Disease. Williams \& Wilkins. Baltimore

3. Booth A.J, Naylor JM (1987): Correction of metabolic: acidess in diarrheal calves by oral administration of elect rolit solutons with or withou bicarbonate. J Ain Vet Med Assoc. 191. 62-68.

4. Bywater RJ (1980): Comparison berween milk deprivalion and oral vehdration with a glucose-glycine-electrolyte formulation in diarthoeic and transported calves. Vet Rec. 107, 549-551.

5. Demirer MA (1986): Besin Hijyent. Özel Bölüm. Kısım I Su Hijycni. Ders Notları. AÜ Veteriner Fakültesi. Ankara.
6. Elagamy EI $(2000)$ : Physicochemical, moleculat and immunological characterization of camel calf rennet: a comparison with buffalo rennet. J Dairy Rcs. 67. 73-81.

7. Emmons DR, I ister EE (1976): Quality of pronein in milk replacers for young calves. I. Factors affecting in vitro curd formation by rennet (chymosin. rennin) from re constituted milk powder. Can J Anim Sci. 56. 317-325

8. Fmmons DB, I ister EE (1976): Quality of protein in milk replacers for young calves. HI. Effects of heal treament of skim milk powder and fat levels on calf srownth. feed inlake and nitrogen balance. Can J Anim Sci. 56. 327-333.

9. Emmons DB, Lister EE (1976): Qualiy of protein in milk replacers for young calves. VI. Rennet (chymosin. remin) coagulation of reconstituted milk poswder combainins: added protein, fat. calcium phosphate and cillate. Can J Anim Sci, 56. 339-345.

10. Fettman MJ, Rrooks PA, Burrows KP, Phillips $\mathrm{RW}$ (1986): Evaluation of commercial oral replacement formulas in healthy neonatal calves. J Am Vet Mad Assoc. 188. 397-401.

11. Frantzen JF, Toullec R, Mathieu C.M (1971): Iifluence de la coagulation des proteines sur l'utilisanom distestive d'un lait de remplacement par le veau preraminanl. $10^{\mathrm{lh}}$ Cong Int Zootech, Versailles.

12. Hartmann $\mathbf{H}$ (1995): Fliswigkeitsherapie bei Tieren. Gustav Fischer Verlag, Jena.

13. Heath SE, Naylor JM, Guedo BL, Petrie I, Rousseaux CG, Radostits OM (1989): The effects of feeding milk to diarrheic calves supplemented with oral electrolytes. Cinn I Vet Res, 53. 477-485

14. Hoffmann W (1987): Kälberdurchlall. Prakt. Tieratzl 68 collegium vetcrimarium XVII (1986). 83-91.

15. Johnston WS, Maclachlan GK (1977): Disestive illness in the calf associated with non-cousulation of cowss milh Vet Rec.101. 325-326.

16. Klee W (1989): Aspekte der Behandlung news'sebrener Káelber mit akutem Durchfall. Vet, 5. 6-17

17. Kolb E (1989): Lehrhuch der Physiologite der Maustiere. Teil I-II. 5. AutT., G. Fischer Verlag. Stuttgart.

18. Kurtdede A (1987): Neonatal buzağl enteritleri'nu per os kullanlan glukoz- elektrolit solusyomu (CES) be ghluksoglisin-elektrolit solusyonu (GGISS) ite să̈almum bizerine salismalar. AÜ Vel Fak Derg. 34. 177-186.

19. Kutas F (1988): Stijrungen des Wasser-und litektmolyhaushaltes 478-493. In: $N$ Rossow. Z Horvalh (Ilrse). Innere Krankheiten der Hausticre. Bd H: Funktionelle Storungen. G. Fischer Verlag. Jenia.

20. I,cek BF (1993): Digestion in the Ruminant Sumach. 387. 416. In: MJ Swenson. WD Recce (Eds). Dukes' Physiology of Domestic Animals. 1/th ed. Cornell liniversily Press. 11 haca.

21. Michell AR (1988): Drips. drinks and drenthes: what mal ters influid therapy. Irish Vet I. 42. 17-22.

22. Michell AR, Bywater RJ, Clarke KW, Hall I,W, Waterman AE (1989): Veterinary Fluid Therapy. Blackwcll Sci Publ, Oxford.

23. Naylor JM (1989): A retrospective stuch if the te lationship befween clinical sighs and selerity of acidosis in diarrheic calves. Catl Vet J. 30. 577-580. 
24. Naylor JM (1992): Effects of electrolve solutions for oral adiministranion on clonting of milk. J Am Vet Med Assoc. 201. 1026-1029.

25. Özalp E, Kaymaz \$ (1997): Sät Urünleri ve Teknolojisi. Ders Votları. Al̈ Veleriner Fakullesi, Ankara.

26. Petit HV, Ivan M, Brisson G.J (1988): Digestibility and blowd parameters in the preruminant calf fed a cloning or a ncm lonins milk replacers. J Anim Sci, 66. 986-991.

27. Pickel M, Zaremba W, Grunert Es (1989): Zur Proph ylaxe der Diarhose heim neugeborenen Kalb. Prakt. Ti. cratzt 70), collegium vetcrinarium XIX (1988), 51-56.

28. Pospischil A (1989): Pathologie und Pathogenese in. fektiöser Durchfallerkrankungen heim Kalh. Vct, 5. 27-32.

29. Sachs I (1984): Angewandte Statistik: Anwendung statistischer Methoden. 6. Aut]. Springer Verlag. Berlin.

30). Sadieck A, Schlerka (; 1996): Untersuchungen über die Rehydratation bei an Durchjall erkrankten Milchkälbern Ticriarnl Umschatu. 51. 544-5.52.

31. Simmons RD. Keefe TH J, Kilgore WR (1985): Oral iehyitiation of neomatal calies and pigs. Mod Vet Pract. 66. 395-399.

32. Slanina L (1985): Krankheiten der Vormägen und des Lablinagen. 5()-101. In: N Rossow, 7. Horvath (Hrsg), Inncic Kiankheiten der Hatusticre. Bd I: Organkrankhciten. G Fischer Verlag. Jena.
33. Sahal M, Ünsüren H, İmren HY (1993): Untersuthungen zur Infusiontherapie bei neuseborenen durchfalligen Kälbern aus der Ungehung ron Ankara tunter speziellen Beriucksichtugung einer Azidose (1. Mitteilemg). Dusch Tieriirzll Wochenschr, 100, 138-142.

34. Tekinşen OC $(2000)$ : Süt Urïnleri Teknolosilsi. Selçuk Üniversitesi Balsimevi, Konya.

35. Trempley RRM (1990)): Intravenous fluid therapie in calves. Vel Clin Vorth Am. 6. 77-110.

36. Walker P(;, Constable PD, Morin DE. Forenlan JH. Drackley JK, Thurmon JC (1998): Comparisen of hypertomic saline-dextran solution and lastated Ringers solution for resuscitating severely dehydrated calves with di. arrhea. J Ain Vet Med Assoc. 213. 113-121

37. Youanes YD, Herdt TH. (1987): Chanses in small intestine morphology: and flora associated with decreased energy digestibility in calves with naturally accurring diwrrhea. Am J Vel Res. 48. 719-725

Gelis tarihi: 12.12.2000/Kabul karihi 30.3.26)()

Yazışma adresi :

Yıd. Doç: Dr. Hissejin Vorverda

Adnan Menderes Universitesi

Veteriner Fakultesi

If Hastallklarl Anabilim Dalt

Isıkll Köyü, o90lo Aydun 